\title{
EFFECT OF DEXAMETHASONE WITH BUPIVACAINE ON DURATION OF SUPRA CLAVICULAR BLOCK COMPARED TO BUPIVACAINE WITH NORMAL SALINE: A PROSPECTIVE, RANDOMIZED AND DOUBLE BLIND STUDY
}

Vishnu Vardhan A르, Vishnu Mahesh Babu B², Sai Naveena Lakshmi B ${ }^{3}$

\section{HOW TO CITE THIS ARTICLE:}

Vishnu Vardhan A, Vishnu Mahesh Babu B, Sai Naveena Lakshmi B. "Effect of Dexamethasone with Bupivacaine on Duration of Supra Clavicular Block Compared to Bupivacaine with Normal Saline: A Prospective, Randomized and Double Blind Study". Journal of Evolution of Medical and Dental Sciences 2014; Vol. 3, Issue 28, July 14; Page: 7861-7869, DOI: 10.14260/jemds/2014/2984

ABSTRACT: BACKGROUND: In this study, we evaluated the effect of Dexamethasone with Bupivacaine compared to Bupivacaine with Normal Saline on the duration of the Supra clavicular block. METHODOLOGY: After obtaining institutional ethical committee's approval and getting informed consent from the patients, 50 patients were randomly divided into two groups $\mathrm{D}$ and $\mathrm{C}$ comprising of 25 each. We excluded patients less than 50-75kgs weight and patients who had comorbidities like Diabetes Mellitus, Hypertension and people on oral anti-coagulants. Patients were premedicated with Tab. Ranitidine 150mg night before surgery and Inj. Midazolam $0.05 \mathrm{mg} / \mathrm{kg}$ IM $1 \mathrm{hr}$ prior to surgery. Group D received $28 \mathrm{ml}$ of $0.5 \%$ bupivacaine with $8 \mathrm{mg}(2 \mathrm{ml})$ Dexamethasone. Group $\mathrm{C}$ received $28 \mathrm{ml}$ of bupivacaine with $2 \mathrm{ml}$ of Normal saline. RESULTS: In our study, the mean duration of analgesia in group D was $1278.8 \pm 82.83$ minutes $(21.3 \mathrm{hrs})$ whereas in group C it was $425.6 \pm 53.31$ minutes $(7.08 \mathrm{hrs})(\mathrm{p}<0.0001)$. The mean duration of motor block in group D and group C were $1082 \pm 80.47$ minutes $(18.03 \mathrm{hrs}$ ) and $359.2 \pm 55.45$ minutes (5.98 hrs) respectively $(\mathrm{p}<$ 0.0001). Both these data were highly significant statistically. CONCLUSION: We conclude that addition of Dexamethasone to local anesthetic drugs in supraclavicular brachial plexus block significantly prolongs the duration of analgesia and duration of motor block in patients undergoing upper limb surgeries.

KEYWORDS: Dexamethasone, Bupivacaine and Supraclavicular Brachial Plexus block.

INTRODUCTION: Brachial plexus block is a popular and widely employed regional block technique for perioperative anesthesia and analgesia for surgeries of the upper extremity.[1] Regional nerve block avoids the unwanted effects of the anesthetic drugs used during general anesthesia and the stress of laryngoscopy and tracheal intubation. ${ }^{[2]}$ Now-a-days different drugs have been used with local anesthetics to achieve quick, dense and prolonged block. ${ }^{[3]}$ Drugs like Epinephrine, Morphine, Pethidine, Clonidine, Butorphanol, Midazolam are used along with local anesthetics for this purpose. ${ }^{[4]}$ But these are associated with side effects like sedation, respiratory depression, psychomimetic effects, pruritus etc.[5] Drugs with minimal side effects and prolonged duration of analgesia are always looked for.

Recently various studies proved the efficacy of steroids like Dexamethasone for its prolonging effects on the duration of regional nerve blocks. [6] Dexamethasone is very potent and highly selective glucocorticoid. Basically it is used as anti-inflammatory and immunosuppressant.[7] Clinical Uses of Dexamethasone are for treatment of many inflammatory and autoimmune conditions but Glucocorticoids are also used to treat patients suffering from neuropathic pain and complex regional pain syndromes (CRPS).[8,9] 
They induce a degree of vasoconstriction, so one theory is that the drug acts by reducing local anesthetic absorption.[10] A more attractive theory holds that dexamethasone increases the activity of inhibitory potassium channels on nociceptive C-fibres (via glucocorticoid receptors), thus decreasing their activity.[11,12]

Our aim was to evaluate the efficacy of Dexamethasone with Bupivacaine compared to Bupivacaine with normal saline on the characteristics of supraclavicular brachial plexus block.

MATERIALS AND METHODS: The Present study was conducted in the Government General Hospital, Rangaraya Medical College, Kakinada during the period of July 2013 to September 2013.

After obtaining institutional ethical committee's approval and informed consent, 50 patients aged between 20-45years posted for upper extremity surgery, belonging to American Society of Anesthesiologist's (ASA) grading I and II of both sexes weighing 50-75kg were taken up for this study.

\section{Exclusion Criteria:}

- Patient refusal.

- Patients belonging to ASA III and IV.

- History of allergy to local anesthetics or Dexamethasone.

- Coagulopathy.

- Diabetes mellitus.

- Local infection at the site of proposed puncture for supraclavicular block.

- Pre-existing neuropathy involving the surgical limb.

- $\quad$ Systemic use of corticosteroids within 6 months before surgery.

They were divided randomly by simple random sampling method into 2 groups, GROUP D and C comprising of 25 each.

In the operation theatre, intravenous access was secured with 18G cannula on the opposite limb and IV fluid was started.

All the basic monitoring devices like SPo2, ECG, NIBP were attached \& baseline parameters were recorded.

Patients were pre-medicated with Tab. Rantidine150mg night before surgery and Inj. Midazolam $0.05 \mathrm{mg} / \mathrm{kg}$ IM $1 \mathrm{hr}$ prior to surgery.

Supraclavicular block was performed using nerve stimulation technique in the supine position with head turned $45^{\circ}$ to the opposite side and arm placed by the side of chest.

Needle insertion site was prepared with antiseptic solution.

About $1-1.5 \mathrm{~cm}$ above the midclavicular point subclavian artery pulsations were felt, $50 \mathrm{~mm}$ long insulated needle was inserted in caudal, backward and medial direction.

When muscle contractions were seen at stimulating current between $0.2 \mathrm{~mA}$ and $0.5 \mathrm{~mA}$ at 2 $\mathrm{Hz}$ frequency with pulse width of $0.1 \mathrm{~ms}$, drugs were injected with intermittent negative aspiration.

Group D received $28 \mathrm{ml}$ of $0.5 \%$ bupivacaine with $8 \mathrm{mg}(2 \mathrm{ml})$ dexamethasone. Group C received $28 \mathrm{ml}$ of bupivacaine with $2 \mathrm{ml}$ of normal saline. 
The following parameters were assessed after institution of the blockade:

- Sensory blockade was tested using pin prick method along the distribution of the four nerves (median nerve, radial nerve, ulnar nerve and musculocutaneous nerve).

- Onset of sensory blockade is considered as the time interval between the end of local anaesthetic administration and loss of sensation to pin prick.

- The duration of analgesia is defined as the time interval between the end of local anaesthetic administration to the time when patient had VAS (Visual analogue scale) score of $\geq 4$.

- Motor blockade assessment was done using the Modified Bromage scale for upper extremities on a three point scale.

\section{Modified Bromage Scale (Three Point Scale):}

- Grade 0 = normal motor function with full flexion/extension of elbow, wrist and fingers.

- Grade 1= decreased motor strength with ability to move fingers and/or wrist only.

- Grade 2= complete motor blockade with inability to move fingers.

- Onset of motor blockade is considered as the time interval between the end of local anaesthetic administration and inability to move fingers.

- The duration of motor blockade is defined as the time interval between the end of local anaesthetic administration and the recovery of complete and motor function of the hand and forearm.

The surgery was allowed to proceed when complete anesthesia was achieved. Intraoperatively HR, ECG, NIBP, SPO2 were monitored. Post operatively, motor blockade and VAS score were assessed every hourly. Inj. Diclofenac $75 \mathrm{mg}$ IM was administered as rescue analgesic.

Statistical Analysis: All the data was compiled systematically and analyzed using Student's t-test, Chi square test. $p$ Value $<0.05$ was considered significant and $p<0.0001$ as highly significant.

RESULTS: 50 Patients were enrolled for the study. All patients completed the study successfully.

The demographic profiles of the patients in both the groups were comparable with regards to age, sex and weight, ASA status and mean duration of surgery.

Comparison of Initial Block Characteristics in both the Groups:

The mean time to onset of sensory block in minutes was $16.92 \pm 4.63$ in group $D$ and $18.46 \pm$ 3.55 in group C $(\mathrm{p}=0.19)$ it was statistically not significant.

The mean time to onset of motor block in minutes in group D and group C was $21.82 \pm 3.61$ and $23.43 \pm 3.89$ respectively $(\mathrm{p}=0.1359)$ it was statistically not significant.

Mean time to onset of sensory and motor blockade were earlier in Dexamethasone group compared to the control group, but it is not statistically significant $(\mathrm{p}>0.05)$.

Peri-operative Block Characteristics:

Duration of motor block and duration of analgesia were prolonged in Dexamethasone group compared to the control group. It is statistically very significant as $\mathrm{p}<0.0001$.

In our study, the mean duration of analgesia in group D was $1278.8 \pm 82.83$ minutes $(21.3$ hrs) whereas in group C it was $425.6 \pm 53.31$ minutes $(7.08 \mathrm{hrs})(\mathrm{p}<0.0001)$, highly significant statistically. 
The mean duration of motor block in group D and group C were $1082 \pm 80.47$ minutes $(18.03$ hrs) and $359.2 \pm 55.45$ minutes $(5.98 \mathrm{hrs})$ respectively ( $<0.0001)$, highly significant statistically.

Incidence of nausea in group D was 4\%, in group C was 16\%, which is statistically significant.

Incidence of tingling/numbness in the early post-operative period is $4 \%$ in group $\mathrm{D}, 8 \%$ in group C which is statistically not significant.

DISCUSSION: Regional anesthesia is a simple, safe, effective technique of anesthesia having distinct advantages over general and intravenous regional anesthesia very particularly for Day Case Surgeries. Hence, regional anesthesia techniques are gaining prominence now-a-days. The main reason is they can be utilized for analgesia during post-operative period besides avoiding all the problems associated with general anesthesia. [13]

Supraclavicular brachial plexus block is also simple to perform, safe and effective technique which produces a reliable block of the upper extremity. [14] Several adjuvants like ketamine, epinephrine, opioids, alpha2 agonists etc. can be added to local anesthetics to prolong the duration of regional blocks and also to intensify the quality of regional blocks. ${ }^{[15,16]}$ In our study we evaluated the efficacy of Dexamethasone added to Bupivacaine for supraclavicular Brachial Plexus block.

Intra operative assessments regarding the onset, duration and quality of both sensory and motor blocks were carried out by an observer anesthetist who was blinded to group allocation and the study drug.

The demographic profiles of the patients in both the groups were comparable with regards to age, sex and weight, ASA status and mean duration of surgery. Statistically not significant ( $\mathrm{p}>0.05)$

The mean time to onset of sensory block in minutes was $16.92 \pm 4.63$ in group D and $18.46 \pm$ 3.55in group C $(\mathrm{p}=0.19)$. Statistically not significant.

The mean time to onset of motor block in minutes in group D and group C was 21.82 \pm 3.61 and $23.43 \pm 3.89$ respectively $(\mathrm{p}=0.1359)$. Statistically not significant.

Steroids are very potent anti-inflammatory and immunosuppressive agents. Perineural injection of steroids is reported to influence post-operative analgesia as well. [17] Synthetic glucocorticoid dexamethasone is preferred in various studies because of its potential and lack of mineralocorticoid activity. [18] Dexamethasone is also known for its anti-emetic property. Dexamethasone is the preferred anti-emetic agent in cases of refractory in nausea and vomiting.

Though the safety of perineural dexamethasone has been questioned, the use of dexamethasone at doses between 4 and $12 \mathrm{mg}$ via intravenous, perineural and epidural routes is described in regional anesthesia and pain medicine text books. ${ }^{[19]}$ However in vivo and in vitro animal studies also proved that locally applied corticosteroids have no long term effects on the structure, electric properties or function of peripheral nerves. [20]

One limitation of our study is we did not follow up the patients for long periods $>3$ months for chronic neurological effects of dexamethasone. The dose we used in our study is a safe dose which was proved in several clinical trials. No significant side effects were noted in the study group in our study.

Kopacz DJ, Katherine Holte et al., found that addition of small amounts of dexamethasone to bupivacaine incorporated in micro capsules prolonged local analgesia compared with microcapsules with plain bupivacaine after subcutaneous administration in humans. [21] 
R. G. Pathak et al., showed that there was no significant difference in the onset time to sensory and motor blocks between two groups in their study which correlated with the findings of our study. [22]

In our study, the mean duration of analgesia in group D was $1278.8 \pm 82.83$ minutes $(21.3$ hrs) whereas in group C it was $425.6 \pm 53.31$ minutes $(7.08$ hrs) $(p<0.0001)$, highly significant statistically.

The mean duration of motor block in group D and group C were $1082 \pm 80.47$ minutes $(18.03$ hrs) and $359.2 \pm 55.45$ minutes $(5.98 \mathrm{hrs}$ ) respectively $(\mathrm{p}<0.0001)$, highly significant statistically.

In a previous study by K. C. Cummings et al., they reported that dexamethasone prolonged analgesia from Interscalene blocks using ropivacaine or bupivacaine, with the effect being stronger with ropivacaine. Dexamethasone with either drug produced nearly the same $22 \mathrm{~h}$ of analgesia.[23]

In a study by Shrestha BR et al., the authors found that there was significantly faster onset of action (14.5 \pm 2.10 minutes verses $18.15 \pm 4.25$ minutes; $\mathrm{p}<0.05$ ) and prolonged duration of analgesia $(12.75 \pm 5.33$ hours verses $3.16 \pm 0.48$ hours; $\mathrm{p}<0.001)$ in the dexamethasone group than in the other group. ${ }^{[24]}$

Simon J. Parrington et al., showed that dexamethasone added to mepivacaine prolongs the duration of analgesia (332min versus 228min in control group) after supraclavicular brachial plexus block. The onset time of sensory and motor blocks were similar in both the groups.[25]

Several studies have shown that addition of 4-8mg of dexamethasone to local anesthetics effectively and significantly prolongs the duration of analgesia.

There is no significant hemodynamic variability between the two groups.

Incidence of nausea in group D was $4 \%$, in group C was $16 \%$, which is statistically significant. Lower incidence of nausea might be due to systemic absorption of dexamethasone.

Incidence of tingling/numbness in the early post-operative period is $4 \%$ in group D, $8 \%$ in group $\mathrm{C}$ which is statistically not significant. The tingling/numbness disappeared few hours post operatively.

CONCLUSION: Addition of Dexamethasone to local anesthetic drugs in supraclavicular brachial plexus block significantly prolongs the duration of analgesia and duration of motor block in patients undergoing upper limb surgeries.

\section{BIBLIOGRAPHY:}

1. Bridenbaugh LD. The upper extremity: Somatic blockade. In: Cousins MJ. Bridenbaugh PO, eds. Neural blockade in clinical anaesthesia and management of pain. Philadelphia: J.B. Lippin-cott, 1988: 387-416.

2. Kulenkampff D, Persky MA. Brachial plexus anaesthesia: its indications, techniques, and dangers. Ann Surg 1928; 37: 883-91.

3. Moore DC, Regional block. A hand book for use in the Clinical Practice of Medicine and Surgery. $4^{\text {th }}$ ed. Spring field 11, Charles C Thomas 1975; 221.

4. Neal JM, Hebl JR, Gerancher JC, Hogan QH. Brachial plexus anaesthesia: Essentials of our current understanding. Reg Anaesth Pain Med 2002: 27: 402-28.

5. Patrick J. Technique of brachial plexus block anaesthesia. Br J Surg 1940; 27: 734. 
6. Benzon, Honorio T, Chew, Teng-Leong, McCarthy, Robert J et al. Comparison of the particle sizes of different steroids and the effect of dilution: a review of the relative neurotoxicities of the steroids. Anesthesiology 2007; 106: 331-8

7. Kopacz DJ, Lacouture, Peter G, Wu, Danlin, Nandy. The dose response and effects of dexamethasone on bupivacaine microcapsules for intercostal blockade (T9 to T11) in healthy volunteers. Anesth Analg 2003 96; 2: 576-82.

8. Yadav RK, Sah BP, Kumar P, Singh SN. Effectiveness of addition of neostigmine or Dexamethasone to local anesthetic in providing perioperative analgesia for brachial plexus block. Katmandu Univ Med J 2008 Jul-Sep, 6(23), 302.

9. Bani-Hashem N, Hassan-nasab B, Alijan Pour E, Amri Maleh P, Akbar Nabavi A, Ali Jabbari. Addition of intrathecal Dexamethasone to Bupivacaine for spinal anesthesia in orthopedic surgery. Saudi J Anaesthesiology, 2011, Oct-Dec 5(4)382-6.

10. Viera, Peter A, Pulai, Istwan, Tsao, George C. Dexamethasone with bupivacaine increases duration of analgesia in ultrasound-guided interscalene brachial plexus blockade. Eur J Anaesthesiology, 2010 march, 27(3), 285-8.

11. Kim YJ, Guie YL, Dong YK, Chi HK, Hee-Jung B, Seok H. Dexamethasone added to levobupivacaine improves postoperative analgesia in ultrasound guided interscalene brachial plexus blockade for arthroscopic shoulder surgery. Korean Journ of Anaesth 2012 Feb; 62(2): 130-4.

12. Merle N, Tandoc, Liang Fan, Sergei Kalesnikov, Alexander K, Nader D Nader. Adjuvant dexamethasone with bupivacaine prolongs the duration of interscalene block: a prospective randomized trial. J Anaesth October 2011 25; 5: 704-709.

13. Movafegh A, Razazian, Mehran, Haji Mohammadi, Fatemah, Meysame et al. Dexamethasone Added to Lidocaine Prolongs Axillary Brachial Plexus Blockade. Anaesth Analg Jan 2006 102; 1: 263-267.

14. Lanz E, Theiss D, Jankovic D. The extent of blockade following various techniques of brachial plexus block. Anesth Analg 1983; 62: 55-8.

15. Murphy DB, McCartney CJ, Chan VW. Novel analgesic adjuvants for brachial plexus block, a systematic review. Anesth Analg. 2000; 90: 1122-1128.

16. McCartney CJ, Brull R, Chan VW, Katz J, Abbas S, Graham B et al. Early but no long-term benefit of regional compared with general anesthesia for ambulatory hand surgery. Anesthesiology. 2004 Aug; 101; 2: 461-467.

17. Golwala M, Swadia V, Dhimar A, Sridahr N. Pain relief by dexamethasone as an adjuvant to local anaesthetics in supraclavicular brachial plexus block. J Anaesth Clin Pharmacol. 2009; 25: 285288.

18. Castello J, Curley J, Hotz J, Uezono M, Tigner J, Chasim M et al. Glucocorticoids prolong rat sciatic nerve blockade in vivo from bupivacaine microspheres. Anesthesiology. 1996; 85(5): 11571166.

19. Racz GB, Noe CL. Pelvic spinal neuraxial procedures. In: Raj P, Lou L, Serdar E, et al. Interventional Pain Management. 2nd ed. Philadelphia, PA: Saunders Elsevier; 2008.

20. Johannsen A, Dahlin L, Kerns JM. Long term local corticosteroid application does not influence nerve transmission or structure. Acta Anaesthesiol Scand. 1995; 39: 364-369. 


\section{ORIGINAL ARTICLE}

21. Kopacz DJ, Allen HW, Holte K, Swanton R, Lacouture P, Werner et al. Dexamethasone Prolongs Local Analgesia after Subcutaneous Infiltration of Bupivacaine Microcapsules in Human Volunteers. Anesthesiology 2002 June 96(6): 1331-1335.

22. R.G.Pathak, Anand P. Satkar, Rajendra N. Khade. Supraclavicular brachial plexus block with and without dexamethasone-a comparative study. International Journal of Scientific and Research Publications, Volume 2, Issue 12, December 20121 ISSN 2250-3153.

23. K. C. Cummings III, D. E. Napierkowski, I Parra-Sanchaz, A Kurz, J E Dalton, J J Brems et al. Effect of dexamethasone on the duration of interscalene nerve blocks with ropivacaine or bupivacaine. Br J Anaesth 2011, June 107(3)446-53.

24. Shrestha BR, Mahajan SK, Shrestha S, Gautam B, Thapa C, Thapa PB et al. Comparative study between tramadol and dexamethasone as an admixture to bupivacaine in supraclavicular brachial plexus block. J Nepal Med Assoc 2007, 46(168): 158-64.

25. Simon J. Parrington, O’ Donnel D, Chan VW, Brown Shrever D, Subrahmanyam R, Qu M et al. Dexamethasone Added to Mepivacaine Prolongs the Duration of Analgesia After Supraclavicular Brachial Plexus Blockade. Reg Anesth Pain Med 2010 Sep-Oct 35: 5: 422-426.

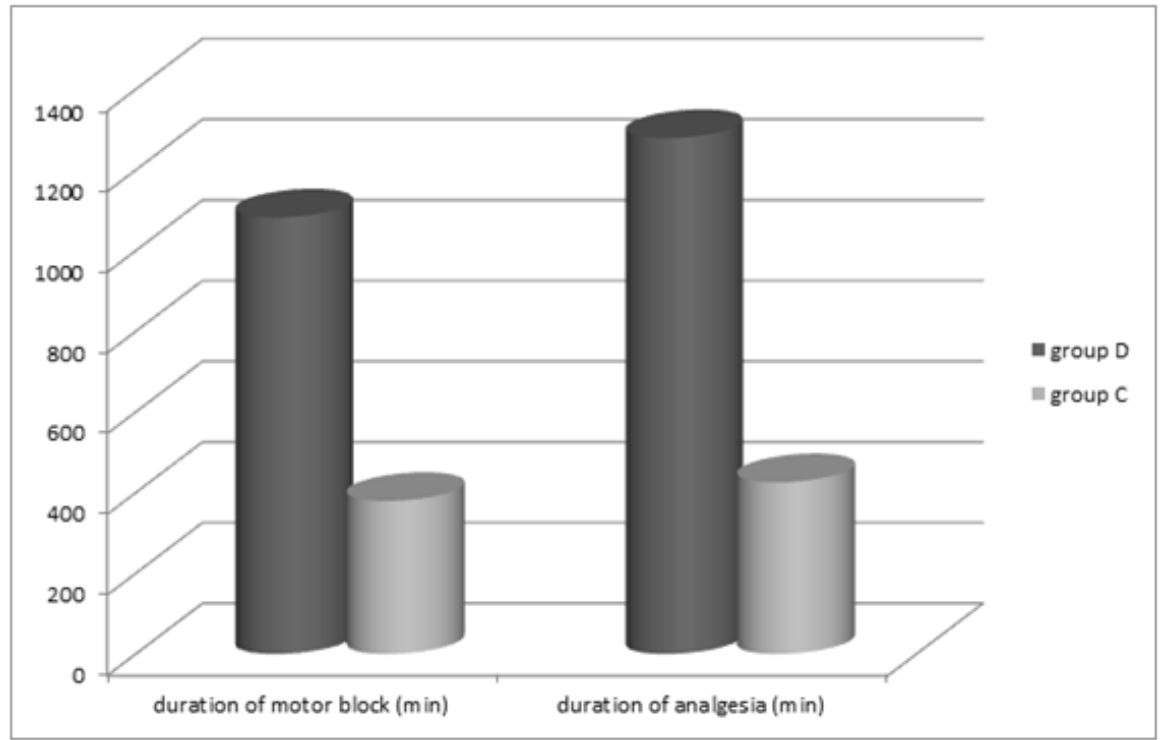

Figure No.1: Mean Duration of Analgesia and Motor Block 


\section{HEART RATE:}

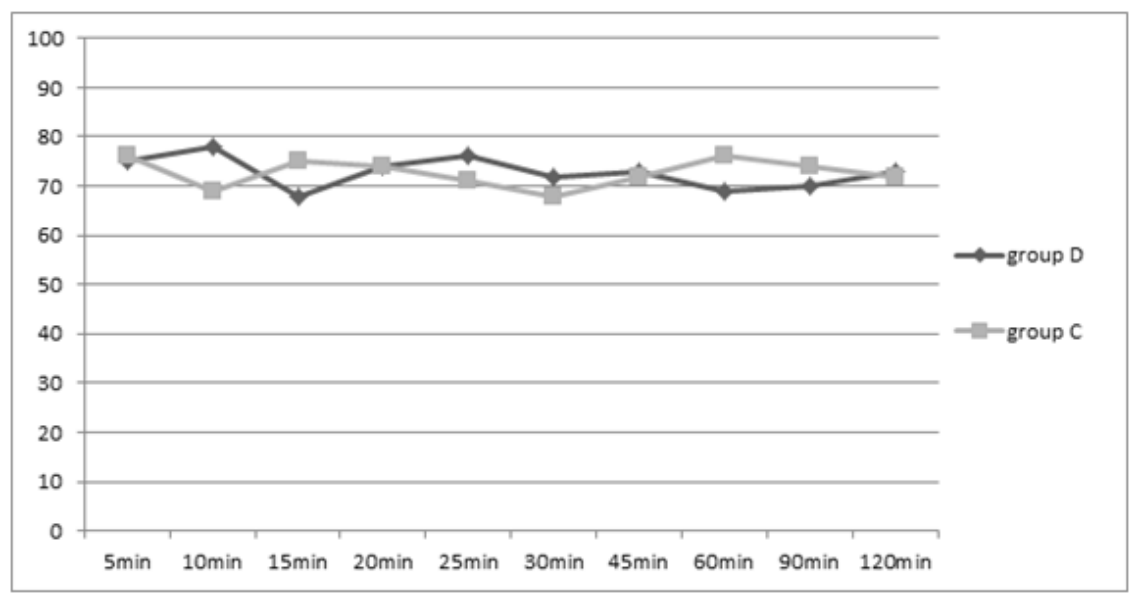

Figure No. 2: Haemodynamic Parameters

MAP (Mean Arterial Pressure):

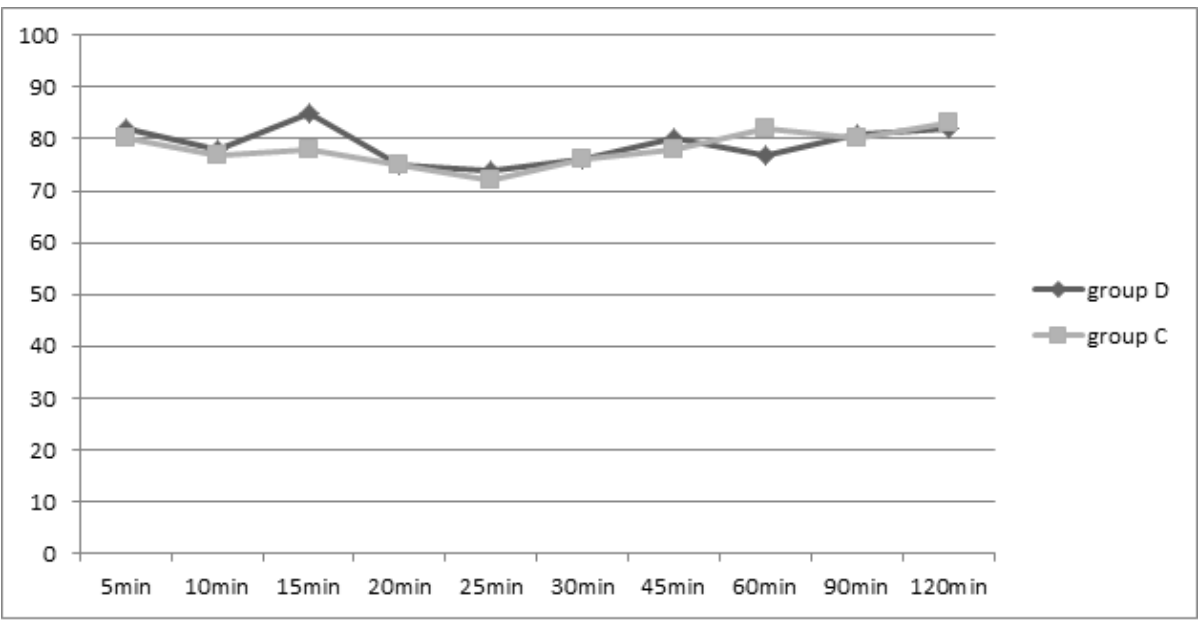

P $>0.05$ Statistically Not Significant

\begin{tabular}{|l|c|c|c|}
\hline \multicolumn{1}{|c|}{ DEMOGRAPHIC CHARACTERS } & GROUP C & GROUP D & P VALUE \\
\hline AGE & $33.88 \pm 9.39$ & $34.28 \pm 8.8$ & 0.8771 \\
\hline WEIGHT & $58.92 \pm 9.56$ & $57.56 \pm 8.02$ & 0.5883 \\
\hline SEX(MALE/FEMALE) & $17 / 8$ & $15 / 10$ & 0.3024 \\
\hline ASA I/II & $22 / 3$ & $21 / 4$ & 0.5416 \\
\hline MEAN DURATION OF SURGERY(min) & $90.5 \pm 13.7$ & $95.2 \pm 15.5$ & 0.2616 \\
\hline \multicolumn{2}{|r}{ Table 1:Demographic Details } \\
\hline
\end{tabular}




\begin{tabular}{|c|c|c|c|}
\hline BLOCK CHARACTERISTICS & GROUP D & GROUP C & P VALUE \\
\hline ONSET OF SENSORY BLOCK (min) & $16.92 \pm 4.63$ & $18.46 \pm 3.55$ & 0.192 \\
\hline ONSET OF MOTOR BLOCK (min) & $21.82 \pm 3.61$ & $23.43 \pm 3.89$ & 0.135 \\
\hline
\end{tabular}

Table 2: COMPARISION OF INITIAL BLOCK CHARACTERISTICS IN BOTH THE GROUPS

\begin{tabular}{|c|c|c|c|}
\hline & GROUP D & GROUP C & P VALUE \\
\hline DURATION OF MOTOR BLOCK(min) & $\begin{array}{c}1082 \pm 80.47 \\
(18.03 \mathrm{hrs})\end{array}$ & $\begin{array}{c}379.2 \pm 55.45 \\
(5.98 \mathrm{hrs})\end{array}$ & $<0.0001$ \\
\hline DURATION OF ANALGESIA(min) & $\begin{array}{c}1278.8 \pm 82.83 \\
(21.3 \mathrm{hrs})\end{array}$ & $\begin{array}{c}425.6 \pm 53.31 \\
(7.08 \mathrm{hrs})\end{array}$ & $<0.0001$ \\
\hline
\end{tabular}

Table 3: PERIOPERATIVE BLOCK CHARACTERISTICS

\begin{tabular}{|l|c|c|c|}
\hline & $\begin{array}{c}\text { GROUP D } \\
(\mathbf{n = 2 5 )}\end{array}$ & $\begin{array}{c}\text { GROUP C } \\
(\mathbf{n = 2 5})\end{array}$ & P VALUE \\
\hline NAUSEA & $1(4 \%)$ & $4(16 \%)$ & 0.008 \\
\hline VOMITING & 0 & $1(4 \%)$ & 0.12 \\
\hline PNEUMOTHORAX & -- & -- & \\
\hline HEMOTHORAX & -- & -- & \\
\hline HORNER SYNDROME & -- & -- & \\
\hline TINGLING/NUMBNESS & $1(4 \%)$ & $2(8 \%)$ & 0.37 \\
\hline
\end{tabular}

Table 4: Side effects

Data expressed as absolute numbers or percentage

\section{AUTHORS:}

1. Vishnu Vardhan A.

2. Vishnu Mahesh Babu B.

3. Sai Naveena Lakshmi B.

\section{PARTICULARS OF CONTRIBUTORS:}

1. Associate Professor, Department of Anaesthesiology, Rangaraya Medical College, Kakinada.

2. Associate Professor, Department of Anaesthesiology, Rangaraya Medical College, Kakinada.

3. Senior Post Graduate, Department of Anaesthesiology, Rangaraya Medical College, Kakinada.

\section{NAME ADDRESS EMAIL ID OF THE CORRESPONDING AUTHOR: \\ Dr. Vishnu Vardhan A, Srujana Hospital, Srinagar, \\ Kakinada-533003. \\ Email: athalurivishnu@gmail.com}

Date of Submission: 30/06/2014. Date of Peer Review: 01/07/2014. Date of Acceptance: 08/07/2014. Date of Publishing: 14/07/2014. 